\title{
Morphodigital Study of the Mandibular Trabecular Bone in Panoramic Radiographs
}

\author{
Estudio Morfodigital del Trabeculado Óseo Mandibular en Radiografías Panorámicas
}

\begin{abstract}
Plauto Christopher Aranha Watanabe; João Paulo Mardegan Issa; Tatiane Martin de Oliveira; Solange Aparecida Caldeira Monteiro; Mamie Mizusaki Iyomasa; Simone Cecílio Hallak Regalo \& Selma Siéssere
\end{abstract}

WATANABE, P. C. A.; ISSA, J. P. M.; OLIVEIRA, T. M.; MONTEIRO, S. A. C.; IYOMASA, M. M.; REGALO, S. C. H. \& SIÉSSERE, S. Morphodigital study of the mandibular trabecular bone in panoramic radiographs. Int. J. Morphol., 25(4):875-880, 2007.

SUMMARY: The aim of this study was to correlate the morphodigital characteristics of the trabecular mandibular bone, in this way, it is possible to observe osteoporosis clue in patients of both sex, using panoramic radiograph for analysis. The results of this study showed statistical difference between men and women considering the bone trabecular measures $(\mathrm{p}<0.05)$, but it was not found statistical difference between the sides in each analyzed group $(\mathrm{p}>0.05)$. Male group presented a more strongly trabecular and complex bone than the female group, this finding is important index to osteoporotic risk, being possible to affirm that the male bone is less probable to suffer a osteoporotic fracture.

KEY WORDS: Mandible; Bone; Digital image; Radiograph.

\section{INTRODUCTION}

Osteoporosis is a condition characterized by a loss in bone mineral density and micro-architectural deterioration in bone tissue leading to fractures (Concensus, 1991; Link et al., 1999). Since the disease is preventable, diagnostic techniques are of major importance (Link et al., 1999). The earliest suggestion of an association between osteoporosis and oral bone loss was made in 1960 (Groen et al., 1960). The dentist is often the most regularly visited doctor in the elderly population, and dental radiographs are the most frequently used imaging modalities for these patients. Various studies have demonstrated that individuals with osteoporosis have altered morphology of the mandible (Hildebolt, 1997; White, 2002). Some qualitative and quantitative indexes, including the mandibular cortical index (MCI), mandibular cortical thickness, or panoramic mandibular index (Horner \& Devlin, 1998) have also been used for panoramic radiographs to assess the bone quality and to observe the signs of resorption and osteoporosis (Klemetti \& Kolmakow, 1997). Previous studies have reported significant correlations between BMD measurement and mandibular cortical thickness or panoramic mandibular index (Klemetti \& Kolmakow, 1997; Horner \& Devlin, 1998a,b; Benson et al., 1991).
A number of mandibular indices based on panoramic radiographs, and image processing and analyzing techniques have been developed to allow quantification of mandibular bone mass and trabecular architecture in order to discriminate individuals with osteoporosis from those without osteoporosis. Cortical width (CW) (Taguchi et al., 1995b), panoramic mandibular index (PMI) (Benson et al., 1991), alveolar crest resorption degree (M/M) ratio (Taguchi et al., 1995a), cortical index (CI) (Klemetti \& Kolmakow, 1997) and fractal dimension (FD) (Pothuaud et al., 1998; Southard et al., 1996) are among them. In various studies, it has been shown that the decreased bone mineral density (BMD) affects the morphometric (Taguchi et al., 1995a,b; Klemetti \& Kolmakow, 1997; Kribbs et al., 1989), densitometric (Horner \& Devlin, 1998a,b) and architectural properties (White \& Rudolph, 1999; Ruttimann et al. 1992; Law et al., 1996) of mandibular bone in the osteoporotic patients on radiographs. When identified in the initial phase, more easy is the treatment process of this pathology. The trabecular and cortex mandibular bone study can evidence the initial signals of this disease, an example, is the panoramic radiograph exam. 
The aim of this study was to correlate the morphodigital characteristics quality of the mandibular trabecular bone, in this way, being possible to observe osteoporosis clue in patients of both sex, using panoramic radiograph for analysis.

\section{MATERIAL AND METHOD}

It was used in this study fifty women $(n=50)$ and fifty men $(n=50)$, in each one, it was analyzed the right and left sides of the mandible, considering the mandibular trabecular bone portion. All the aspects of this work were approved by the Ethics Committee in Research.
The panoramic exams were obtained using an extrabuccal X-ray apparel, Orthopos, Siemens, standard at $62 \mathrm{KVp}, 16 \mathrm{~mA}$, and rotation time with 14.1 seconds, using radiograph films Kodak T-MAT G and ecran LANEXMedium. The radiographic processing was performed manually, temperature/time, using dark camera and a GBXII filter. After the final washing, the radiographs were dried and digitalized in a professional scanner, Epson, Expression 636, at $300 \mathrm{dpi}$. For the morphodigital study of the trabecular mandible bone, it was used a specific software for the image processing, as it was described by White et al. (2000) methodology. Three regions were studied, the anterior portion, ascendent ramus and the mandible body, and after it was made a mean of the values found in each region (Fig. $1 \mathrm{~A}-\mathrm{H})$.

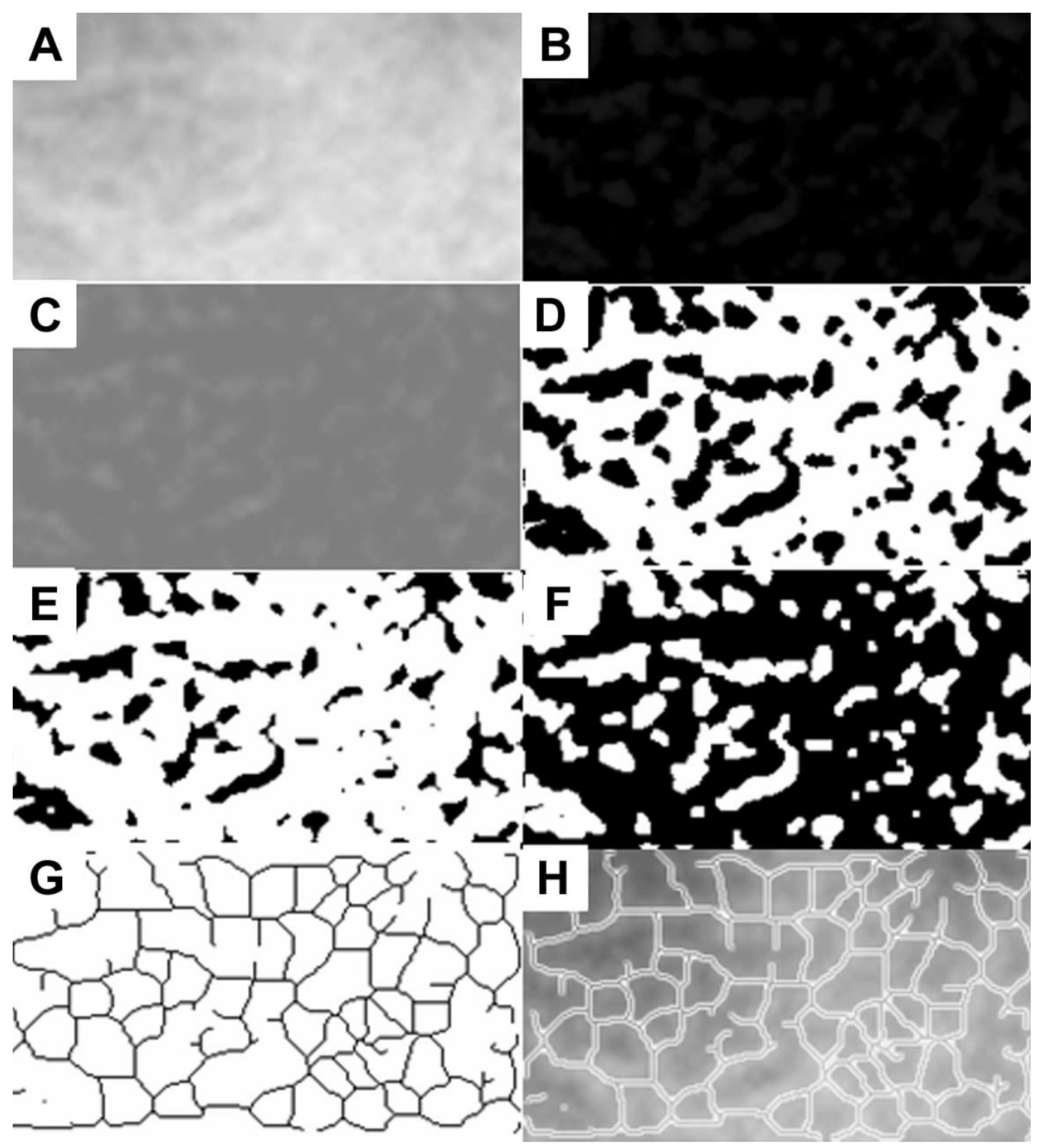

Fig. 1. Sequence of the methodology used in the morphodigital image processing. 
Data were submitted to statistical analysis, GLM ANOVA with Tukey test, $95 \%$ of significance level.

\section{RESULTS}

The results of this study showed statistical difference between men and women considering the bone trabecular measures $(\mathrm{p}<0.05)$, but it was not found statistical difference between the between the right and left sides in each analyzed group $(\mathrm{p}>0.05)$. Male group showed a great number of trabeculas and architecture more complex and strongly than female group, in this way, the bone structure of man is less submitted to the risk of osteoporotic fractures (Fig. 2). This study revealed differences in the mandibular cortex width, being found the greatest values in the male group (Table I).
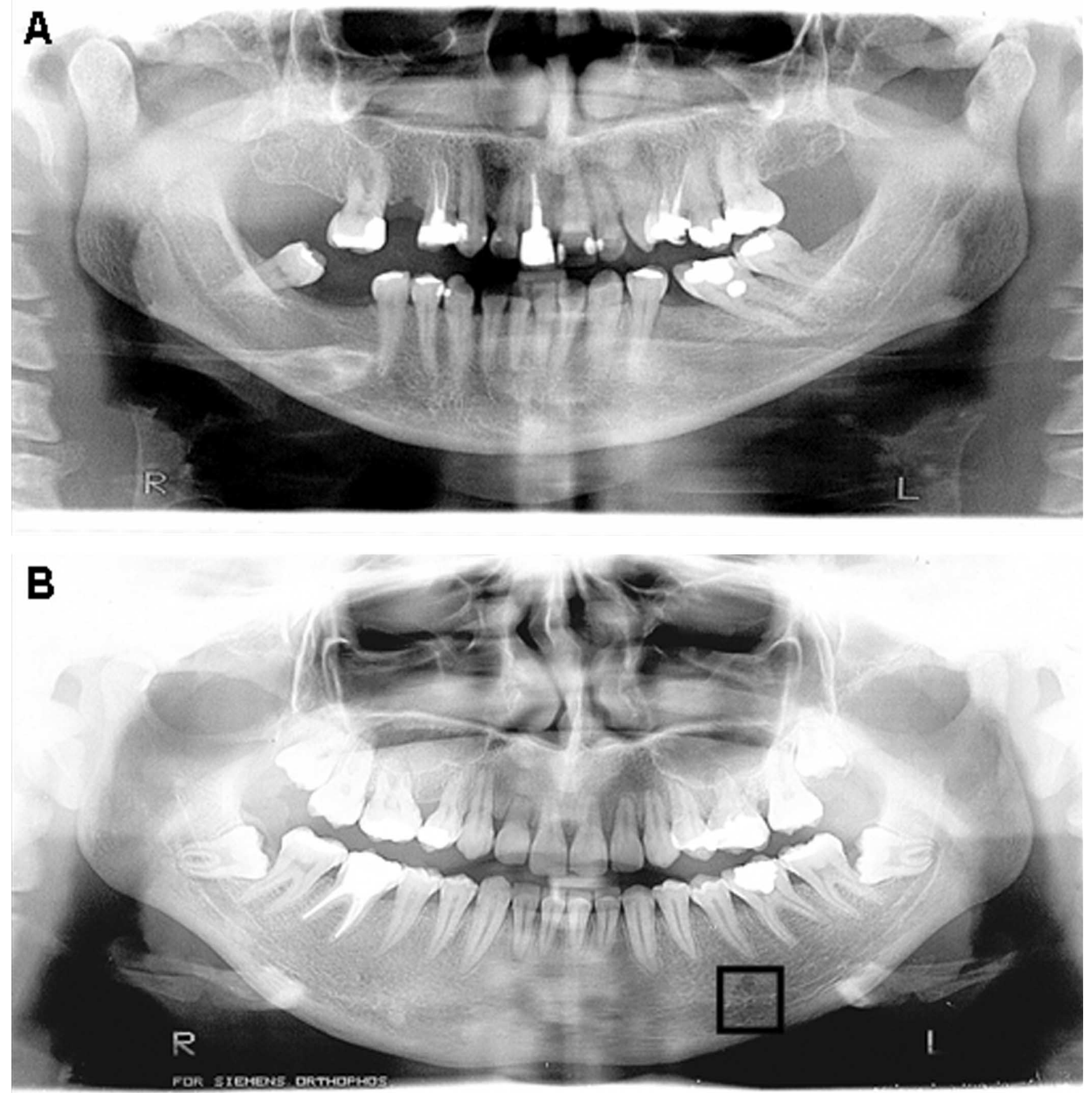

Fig. 2 A. Normal aspect of the mandibular bone structure. B. Osteoporotic mandible represented by the bone lost (square). 
Table I. Means and standard deviations of the bone trabecular measures in the three regions of the mandible.

\begin{tabular}{lcc}
\hline Groups & Mean (M) & Standard deviation (SD) \\
\hline Male Group- right side $^{\text {a }}$ & 2.95 & 0.76 \\
Male Group- left side $^{\text {a }}$ & 2.97 & 0.92 \\
Female group- right side $^{b}$ & 2.10 & 1.23 \\
Female group- left side $^{b}$ & 2.06 & 1.08 \\
\hline
\end{tabular}

a,b- Different letters show statistical difference $(\mathrm{p}<0.05)$.

\section{DISCUSSION}

The aim of this study was to correlate the morphodigital characteristics of the mandibular trabecular bone, in this way, being possible to observe osteoporosis clue in patients of both sex, using panoramic radiograph for analysis.

This article focused on the risk to have osteoporosis, because this pathology is a commonly situation found especially in women people. Post-menopausal women constitute more than $15 \%$ of the population in developed countries whereas this rate is 5-8\% in less developed regions of the world (World Health Organization). By 2030, the world population of menopausal and post-menopausal women is expected to increase to 1.2 billion, with 47 million new cases each year (World Health Organization, 1996; Hill, 1996). Osteoporosis and fractures are more difficult and costly to treat than to prevent. Therefore, several health care interventions have been proposed to identify those people who may be at risk and who could benefit from preventive interventions (Espallargues et al., 2001).

It was found in this study porosity in some radiograph images, especially in the female group. One of the most commonly studied parameters of mandibular bone in relation to osteoporosis is the porosity of the mandibular cortical bone. Some of the investigators have found an association between cortical index and osteoporosis (Klemetti \& Kolmakow, 1997; Bollen et al., 2000; White et al., 2005; Nakamoto et al., 2003; Taguchi et al., 1996), but Drozdzowska et al. reported that there was no relationship between osteoporosis and cortical bone. For the other parameters, some measurements must be performed and some calculations are necessary, and as it was stated before, the complexity of an index may increase its measurement error and decrease its repeatability. In this study, it was performed the cortical bone analysis, that represents a simple classification of the bone based on the appearance of the lower border of mandibular trabecular bone after the cortical bone removal, which it is according to Horner \& Devlin (1998a,b) study.
The structure of the trabecular bone has been analyzed in relation to the possibility to have osteoporosis, being found a complex bone trabecular structure in the male group. While some authors stated that fractal dimension decreases in osteoporosis (Link et al., 1998, Fazzalari \& Parkinson, 1998) others reported an increase (Pothuaud et al.; Ruttimann et $a l$.). It was used in this study digitalized images of the panoramic radiographs. Each imaging modality may have its own non-linear artefacts such as sampling frequency and noise and this may have an affect on the results of fractal dimension (Geraets \& van der Stelt, 2000). Geraets and van der Stelt have stated that most reports based on radiographs in vivo find an association between osteoporosis and increased values of fractal dimension (Pothuaud et al.; Ruttimann et al.). Osteoporosis might not be affecting all bones at the same time with the same severity, thus it is important to correlate the data found in a specific study with another studies that used the same type of bone, in this case, the mandible bone.

The sample of this study was standardized, composed by young adults of both sexes, with similar characterizations. A standardized sample is important because many different factors, such as bone metabolism, skeletal mineral status, extraction of the teeth, surgical procedures, occlusal forces transmitted by dentures, and physical and muscular activity are involved in determining the rate of residual ridge resorption (Klemetti \& Kolmakow, 1997). The structure of the mandibular bone differs significantly over the years and between the genders (Klemetti et al., 1993), especially in postmenopausal women. Bras et al., (1982) reported that the cortex and trabecular bone of the angle of the mandible was distinctly thinner on panoramic radiographs of postmenopausal women and patients with chronic kidney failure. Knezovié-Zlatarié et al., (2002) also reported that the age-related distribution of mandibular cortical index showed an age-related increase in the numbers of individuals with $\mathrm{C} 3$ cortex appearance, and a significantly higher incidence of women who had C3 cortexes in an older age group. On the other hand, Mohajery \& Brooks (1992) could 
not determine differences in the thickness of the angle of the mandible, sinus floor or lamina dura of the tooth sockets between healthy women and those with early osteoporosis.

It was possible to conclude in this study, that the male group presented a more strongly trabecular and complex bone than the female group, this finding is important index to osteoporotic risk, being possible to affirm that the male bone is less probable to suffer a osteoporotic fracture. Thus, it is important to call the attention of all health professionals about the importance to identify the initial signals of the osteoporosis disease in their patients, in this way, this pathology will be treated in its initial phase and the clinical success will be probably reach.

WATANABE, P. C. A.; ISSA, J. P. M.; OLIVEIRA, T. M.; MONTEIRO, S. A. C.; IYOMASA, M. M.; REGALO, S. C. H. \& SIÉSSERE, S. Estudio morfodigital del trabeculado óseo mandibular en radiografías panorámicas. Int. J. Morphol., 25(4):875-880, 2007.

RESUMEN: El objetivo de este estudio fue correlacionar las características morfodigitales del trabeculado óseo mandibular para de esta manera, verificar indicios de señales de osteoporosis, utilizando para esto, radiografías panorámicas de pacientes de ambos sexos. Los resultados del estudio mostraron diferencias entre los grupos masculino y femenino, en la cuantificación de hueso trabecular mandibular $(\mathrm{p}<0,05)$, pero no se encontraron diferencias enter los lados derecho e izquierdo en cada grupo analizado ( $>00,05)$. El grupo masculino presentó un padrón óseo trabecular más compleo y fuerte que el grupo femenino. Este hallazgo puede ser un importante indicador en cuanto a los riesgos de osteoporosis, por ejemplo, siendo posible afirmar que los huesos de los individuos del grupo masculino están menos sujetos a riesgo de fractura por osteoporosis.

PALABRAS CLAVE: Mandíbula; Hueso; Imagen digital; Radiografía

\section{REFERENCES}

Benson, B.W.; Prihoda, T. J. \& Glass, B. J. Variations in adult cortical bone mass as measured by a panoramic mandibular index. Oral.Surg. Oral.Med.Oral.Pathol., 71:349-56, 1991.

Bollen, A. M.; Taguchi, A.; Hujoel, P. P. \& Hollender, L. G. Case-control study on self reported osteoporotic fractures and mandibular cortical bone. Oral.Surg. Oral.Med. Oral. Pathol. Oral. Radiol. Endod., 90:518-24, 2000.

Bras, J.; Van Ooij, C. P.; Abraham-Inpijn L.; Wilmink J. M. \& Kusen, G. J. Radiographic interpretation of the mandibular angular cortex: A diagnostic tool in metabolic bone loss. Part II. Renal osteodystrophy. Oral. Surg. Oral. Med.Oral. Pathol., 53:647-50, 1982.

Concensus Development Conference, Prophylaxis and treatment of osteoporosis. Am.J.Med., 90:107-10, 1991.

Drozdzowska, B.; Pluskiewicz, W. \& Tarnawska, B. Panoramic based mandibular indices in relation to mandibular bone mineral density and skeletal status assessed by dual energy X-ray absorptiometry and quantitative ultrasound. Dentomaxillofac. Radiol., 31:361-7, 2002.

Espallargues, M.; Sampietro-Colom, L.; Estrada, M.D.; Sola, M.; del Rio, L. \& Sertoain, J. Identifying bone-massrelated risk factors for fracture to guide bone densitometry measurements: a systematic review of the literature. Osteoporos. Int., 12:811-22, 2001.

Fazzalari, N. L. \& Parkinson, I.H. Fractal properties of cancellous bone of the iliac crest in vertebral crush fractures. Bone, 23:53-7, 1998.

Geraets, W. G. \& van der Stelt, P. F. Fractal properties of bone. Dentomaxillofac. Radiol., 29:144-53, 2000.

Groen, J. J.; Duyvensz, F.; Halsted, J. A. Diffuse alveolar atrophy of the jaw (non-inflammatory form of paradental disease) and presenile osteoporosis. Geront. Clin., 2:68-86, 1960.

Hildebolt, C. F. Osteoporosis and oral bone loss. Dentomaxillofac. Radiol., 26:3-15, 1997.

Hill, K. The demography of menopause. Maturitas, 23:113-27, 1996.

Horner, K. \& Devlin, H. The relationship between mandibular bone mineral density and panoramic radiographic measurements. J. Dent. 26: 337-43, 1998a.

Horner, K. \& Devlin, H. The relationships between two indices of mandibular bone quality and bone mineral density measured by dual energy X-ray absorptiometry. Dentomaxillofac. Radiol., 27:17-21, 1998b. 
Klemetti, E.; Kolmakow, S. Morphology of the mandibular cortex on panoramic radiographs as an indicator of bone quality. Dentomaxillofac. Radiol., 26: 22-5, 1997.

Klemetti, E.; Kolmakov, S.; Heiskanen, P.; Vainio, P. \& Lassila, V.Panoramic mandibular index and bone mineral densities in postmenopausal women. Oral. Surg. Oral. Med. Oral. Pathol., 75:774-9, 1993.

Klemetti, E.; Kolmakov, S. \& Kroger, H. Pantomography in assessment of the osteoporosis risk group. Scand.J. Dent. Res., 102:68-72, 1994.

Knezovié-Zlatarié, D.; Celebié, A.; Lazié, B.; Bauéié, I.; Komar, D. \& Stipetié-Ovéariéek, J. Influence of age and gender on radiomorphometric indices of the mandible in removable denture wearers. Coll. Antropol., 26:259-66, 2002.

Kribbs, P. J.; Chesnut, C. H.; Ott, S.M. \& Kilcoyne, R.F. Relationships between mandibular and skeletal bone in an osteoporotic population. J. Prosthet. Dent., 62:703-7, 1989.

Law, A. N.; Bollen, A. M. \& Chen, S.K. Detecting osteoporosis using dental radiographs: a comparison of four methods. JADA., 127:1734-42, 1996.

Link, T. M.; Majumdar, S.; Grammp, S.; Guglielmi, G.; van Kuijk, C. \& Imhof, H. Imaging of trabecular bone structure in osteoporosis. Eur. Radiol., 9:1781-8, 1999.

Link, T. M.; Majumdar, S.; Lin, J. C.; Newitt, D.; Augat, P. \& Ouyang, X. A comparative study of trabecular bone properties in the spine and femur using high resolution MRI and CT. J. Bone. Miner. Res., 13:122-32, 1998.

Mohajery, M. \& Brooks, S.L. Oral radiographs in the detection of early signs of osteoporosis. Oral.Surg.Oral.Med.Oral. Pathol., 73:112-7, 1992.

Nakamoto, T.; Taguchi, A.; Ohtsuka, M.; Suei, Y.; Fujita, M. \& Tanimoto, K. Dental panoramic radiograph as a tool to detect postmenopausal women with low bone mineral density: untrained general dental practitioners' diagnostic performance. Osteoporos. Int., 14:659-64, 2003.

Pothuaud,L. ; Lespesailles, E. ; Harba, R. ; Jennane, R.; Royant V. \& Eynard, E. Fractal analysis of trabecular bone texture on radiographs: discriminant value in postmenopausal osteoporosis. Osteoporosis. Int., 8:618-25, 1998.

Ruttimann, U.E.; Webber, R. L. \& Hazelrig, J.B. Fractal dimension from radiographs of peridental alveolar bone: a possible diagnostic indicator of osteoporosis. Oral. Surg. Oral.Med. Oral. Pathol., 74: 98-110, 1992.
Southard, T. E.; Southard, K. A.; Jakobsen, J. R.; Hillis, S. L. $\&$ Najim, C. A. Fractal dimension in radiographic analysis of alveolar process bone. Oral. Surg. Oral. Med. Oral. Pathol. Oral. Radiol. Endod., 82:569-76, 1996.

Taguchi, A.; Suei, Y.; Ohtsuka, M.; Otani, K.; Tanimoto, K. \& Ohtaki, M. Usefulness of panoramic radiography in the diagnosis of postmenopausal osteoporosis in women. Width and morphology of inferior cortex of the mandible. Dentomaxillofac. Radiol., 25:263-7, 1996.

Taguchi, A.; Tanimoto, K.; Suei, Y.; Otani, K.; Wada, T. Oral signs as indicators of possible osteoporosis in elderly women. Oral.Surg. Oral.Med.Oral.Pathol.Oral.Radiol. Endod., 80:612-6, 1995a.

Taguchi,A.; Tanimoto, K.; Suei, Y.; Otani, K. \& Wada, T. Tooth loss and mandibular osteopenia. Oral. Surg. Oral. Med. Oral. Pathol. Oral. Radiol. Endod., 79:127-32, 1995b.

White, S. C. Oral radiographic predictors of osteoporosis. Dentomaxillofac. Radiol., 31:84-92, 2002.

White, S. C.; Cohen, J. M. \& Mourshed, F.A. Digital analysis of trabecular pattern in jaws of patients with sickle cell anemia. Dentomaxillofac. Radiol., 29:119-24, 2000.

White, S. C. \& Rudolph, D. J. Alterations of the trabecular pattern of the jaws in patients with osteoporosis. Oral.Surg. Oral. Med. Oral. Pathol. Oral. Radiol. Endod., 88:628$35,1999$.

White, S. C.; Taguchi, A.; Kao, D.; Wul, S.; Service, S. K. \& Yoon, D. Clinical and panoramic predictors of femur bone mineral density. Osteoporos. Int., 16:339-46, 2005.

World Health Organization. Research on the menopause in the 1990 s, report of A WHO Scientific Group. WHO technical report series 866. Geneva: World Health Organization, 1996.

Correspondence to:

Plauto C.A. Watanabe

Departamento de Morfologia, Estomatologia e Fisiologia

Faculdade de Odontologia de Ribeirão Preto, USP

Avenida do Café s/n

CEP14040-904

Ribeirão Preto, SP

BRASIL

Email: watanabe@forp.usp.br

Received: 10-06-2007

Accepted: 22-07-2007 